\title{
Evaluation of Natural Radioactivity Levels for Structural Material Used in the Construction of the Neutrino Detector
}

\author{
Vladimir G. Zinovyev, Anatolii P. Serebrov, Ivan A. Mitropolsky, Yuriy E. Loginov, \\ Georgiy I. Shulyak, Tatyana M. Tyukavina, Sergey L. Sakharov, Anatoly V. Chernyj \\ National Research Centre "Kurchatov Institute", B.P. Konstantinov Petersburg Nuclear Physics Institute, \\ Gatchina, Russia \\ Email: pitzinovjev@yandex.ru
}

Received 7 January 2015; accepted 26 January 2015; published 29 January 2015

Copyright @ 2015 by authors and Scientific Research Publishing Inc.

This work is licensed under the Creative Commons Attribution International License (CC BY). http://creativecommons.org/licenses/by/4.0/

(c) (i) Open Access

\begin{abstract}
In this work, the evaluation of natural radioactivity and spontaneous fission rates was performed for 8 nuclides from the natural radioactive ${ }^{238} \mathrm{U},{ }^{235} \mathrm{U}$ and ${ }^{232} \mathrm{Th}$ decay chains. For this purpose, three samples of structural materials of the neutrino detector, i.e. aluminum, titanium and glass were analyzed by gamma spectroscopy and by neutron activation analysis to quantify a specific radioactivity of the samples. According to the results of this investigation, glass and aluminum samples have maximum values of the mean uranium concentrations $7.3(7) \times 10^{-4 \%}$ and $3.1(6) \times$ $10^{-5 \%}$, respectively, while the lowest value for mean concentration of the uranium was found in titanium samples to be $4.7(3) \times 10^{-6 \%}$. Aluminum sample had maximum values of the mean thorium concentrations, $2.5(8) \times 10^{-3} \%$, while the lowest value for mean concentration of the thorium was found in titanium samples to be $6.2(3) \times 10^{-7 \%}$.
\end{abstract}

\section{Keywords}

Spontaneous Fission, Radioactive Decay Chain, $\alpha$-Decay, $\beta$-Decay, Radionuclide, Branching Factor, Decay Rate

\section{Introduction}

Practically all the neutron-rich nuclei are unstable due to an excess of neutrons in the nucleus. They decay by emission of electrons, beta decay, and generate the electron anti-neutrinos $\bar{v}_{e}$. The quantity of the radioactive nuclei can be defined with the anti-neutrino flux in the reactor core. The anti-neutrino flux density distribution 
allows carrying out monitoring of the reactor core.

Depending on the neutrino flavour, there are several possible detection reactions in a liquid-scintillator detector. The most important ones are the inverse beta decay channel for $\bar{v}_{e}$ :

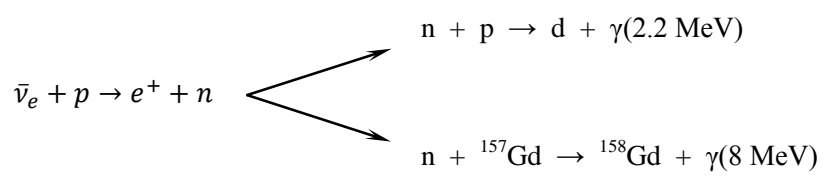

Gamma radiation from capture of slow neutrons in ${ }^{157} \mathrm{Gd}$ is used as signal to neutrino registration after thermalization of fast neutrons in neutrino detector. The ${ }^{158} \mathrm{Gd}$ emits gamma-ray cascade with the total energy of 8 $\mathrm{MeV}\left(\mathrm{S}_{\mathrm{n}}=7937.33 \mathrm{keV}\right)$. The inverse beta decay reaction has a threshold of $1.8 \mathrm{MeV}$. It provides a delayed coincidence signal while the positron gives a prompt signal and then the neutron is captured by a free proton or ${ }^{157} \mathrm{Gd}$ in $\sim 200 \mu \mathrm{s}$ [1]. The neutrino detector has to measure the desired signal at the input count rate of 300 day $^{-1}$ under the assumption of the $0.5 \mathrm{~m}^{3}$ detector volume, the $5 \mathrm{~m}$ distance between centers of the reactor core and the neutrino detector and reactor power of $17 \mathrm{MW}$. Due to the passive and active shielding the neutrino detector provides ultra-low background counting rate in the detector. The cosmic muon capture reaction $(\mu, n)$ on the heavy elements is source of the natural radiation background (fast neutrons). Lead is one of these elements usually used for the construction of the passive shielding. In fact, real counting threshold of the detector is determined by intrinsic radioactive contaminants. As ${ }^{14} \mathrm{C}$ is naturally abundant in organic scintillators, detection of neutrino is not possible below the end point $156 \mathrm{keV}$ of the ${ }^{14} \mathrm{C} \beta$-spectrum.

The isotopes from the natural uranium and thorium decay chains are intensive alpha and beta radioactive sources. At the same time, the ${ }^{238} \mathrm{U},{ }^{235} \mathrm{U},{ }^{234} \mathrm{U}$ and ${ }^{232} \mathrm{Th}$ are disintegrated via spontaneous fission process. The spontaneous fission rate is far less than the $\alpha$-decay one. The ${ }^{238} \mathrm{U},{ }^{235} \mathrm{U},{ }^{234} \mathrm{U},{ }^{232} \mathrm{Th}$ and their daughter nuclei create signals in the liquid-scintillator detector in their natural $\alpha$ - and $\beta$-decays. These signals correlate with those from the fast neutrons which appear in the spontaneous fission of the ${ }^{238} \mathrm{U},{ }^{235} \mathrm{U},{ }^{234} \mathrm{U}$ and ${ }^{232} \mathrm{Th}$. Nuclear characteristics of the ${ }^{238} \mathrm{U}$, ${ }^{232} \mathrm{Th}$ and their daughter nuclei emitting neutrons in the spontaneous fission are given in the Table 1. Only nuclei of the ${ }^{232} \mathrm{Th}$ emit the neutrons after spontaneous fission in the radioactive ${ }^{232} \mathrm{Th}$ decay chain. The spontaneous fission probability SF of the ${ }^{232} \mathrm{Th}$ is $1.1 \times 10^{-9} \%$ per decay. So, the neutrino detector, the passive and the active shielding should be built with materials in which natural radioactivity has ultra-low background.

The ${ }^{235} \mathrm{U}$ and its daughter nucleus ${ }^{231} \mathrm{Th}$ are important naturally occurring radioactive isotopes; they were used to determine the uranium concentration in the samples analyzed. The ${ }^{235} \mathrm{U}$ decays by $100 \% \alpha$-emission to levels in ${ }^{231} \mathrm{Th}$. The recommended nuclear decay data of the ${ }^{235} \mathrm{U}$ and ${ }^{231} \mathrm{Th}$ are presented in Table 2 . The decay data were taken from the LNHB (available at http://www.nucleide.org/NucData.htm).

\begin{tabular}{|c|c|c|c|c|c|c|c|c|}
\hline$D C h$ & Isotope & $T_{1 / 2}$ & $T_{1 / 2(\mathrm{SF})}$ & SF (\%) & $n_{A b n}$ & $D M$ & $B F(\%)$ & Refs. \\
\hline \multirow[t]{6}{*}{${ }^{238} \mathrm{U}$} & ${ }^{238} \mathrm{U}$ & $4.468(5) \times 10^{9} y$ & $8.20(6) \times 10^{15} y$ & $5.45(4) \times 10^{-5}$ & $1.98(3)$ & $\alpha$ & 100 & [2]-[4] \\
\hline & ${ }^{234} \mathrm{Th}$ & 24.10(3) d & & & & $\beta^{-}$ & 100 & [5] [6] \\
\hline & ${ }^{234 \mathrm{~m}} \mathrm{~Pa}$ & 1.159(11) min & & $<1 \times 10^{-9}$ & & $\begin{array}{l}\beta^{-} \\
\text {IT }\end{array}$ & $\begin{array}{c}99.85(1) \\
0.15(1)\end{array}$ & [5] [7] \\
\hline & ${ }^{234} \mathrm{~Pa}$ & $6.70(5) \mathrm{h}$ & & $<3 \times 10^{-10}$ & & $\beta^{-}$ & 100 & [5] [7] \\
\hline & ${ }^{234} \mathrm{U}$ & $2.455(6) \times 10^{5} y$ & $1.5(0.2) \times 10^{16} y$ & $1.6(2) \times 10^{-9}$ & $1.63(15)$ & $\alpha$ & 100 & [8]-[10] \\
\hline & ${ }^{230} \mathrm{Th}$ & $7.54(3) \times 10^{4} y$ & & $<4 \times 10^{-12}$ & & $\alpha$ & 100 & [11] \\
\hline \multirow[t]{4}{*}{${ }^{232} \mathrm{Th}$} & ${ }^{232} \mathrm{Th}$ & $1.402(1) \times 10^{10} y$ & $1.22 \times 10^{21} \mathrm{y}$ & $1.1 \times 10^{-9}$ & $2.13(20)$ & $\alpha$ & 100 & [11] \\
\hline & ${ }^{228} \mathrm{Ac}$ & $6.15(3) \mathrm{h}$ & & & & $\begin{array}{l}\beta^{-} \\
\alpha\end{array}$ & $\begin{array}{c}100 \\
5.5(22) \cdot 10^{-6}\end{array}$ & [12] \\
\hline & ${ }^{212} \mathrm{~Pb}$ & $10.64(1) \mathrm{h}$ & & & & $\beta^{-}$ & 100 & [13] \\
\hline & ${ }^{208} \mathrm{Tl}$ & $3.053(4) \mathrm{min}$ & & - & & $\beta^{-}$ & 100 & [11] \\
\hline
\end{tabular}

$T_{1 / 2}$ is the half-life time, $T_{1 / 2(S F)}$ is the spontaneous fission half-life time, $S F$ is the spontaneous fission probability per decay (\%), $n_{A b n}$ is the neutrons perunitfission, $B F$ is branching factor of the radioactive decay (\%), $D M$ is decay mode, Refs. are references, $D C h$ is Decay chain. 
Table 2. The nuclear data of the ${ }^{235} \mathrm{U}$ and ${ }^{231} \mathrm{Th}$.

\begin{tabular}{cccccccc}
\hline Isotope & $T_{1 / 2}$ & $T_{1 / 2(S F)}$ & $S F(\%)$ & $n_{A b n}$ & Decay mode & BF & Reference \\
\hline${ }^{235} \mathrm{U}$ & $7.04(1) \times 10^{8} \mathrm{y}$ & $0.98(28) \times 10^{19} \mathrm{y}$ & $7.0(2) \times 10^{-9}$ & 1.86 & $\alpha$ & 100 & {$[8][11][14]$} \\
${ }^{231} \mathrm{Th}$ & $25.52(1) \mathrm{h}$ & & - & & $\beta-$ & 100 & {$[15]$} \\
\hline
\end{tabular}

\section{Examination}

The uranium mass concentration and absolute decay rate of the ${ }^{235} \mathrm{U}$ were measured with the gamma spectrometric method in samples analyzed (aluminum and titanium sheets and glass samples).

The gamma line of ${ }^{235} \mathrm{U}$ at the $E_{\gamma}=185.7 \mathrm{keV}$ was used in this case. In the same way the uranium mass concentration and the absolute decay rate of the ${ }^{238}$ Uwere measured with the ${ }^{234 \mathrm{~m}} \mathrm{~Pa}$ full absorption peaks at the $766.6 \mathrm{keV}$ and $1001 \mathrm{keV}$, as the ${ }^{234 \mathrm{~m}} \mathrm{~Pa}$ is daughter nucleus of natural radioactive ${ }^{238} \mathrm{U}$.

$$
{ }^{238} \mathrm{U} \underset{4.47 \times 10^{9} \mathrm{y}}{\stackrel{\alpha}{\longrightarrow}}{ }^{234} \mathrm{Th} \underset{24.1 \mathrm{~d}}{\stackrel{\beta^{-}}{2434 \mathrm{~m}}} \mathrm{~Pa} \underset{1.17 \mathrm{~d}}{\stackrel{\beta^{-}}{\longrightarrow}}{ }^{234} \mathrm{U} \underset{2.5 \times 10^{5} \mathrm{y}}{\stackrel{\alpha}{\longrightarrow}}
$$

The first two daughter nuclei of the radioactive ${ }^{238} \mathrm{U}$ decay chain $\left({ }^{234} \mathrm{Th},{ }^{234 \mathrm{~m}} \mathrm{~Pa}\right)$ are very short-lived compared with ${ }^{238} \mathrm{U}$ so that radioactivity equilibrium is quickly achieved (about in three months) in the samples of natural isotopic composition which need not be subjected to special isotope separation. The ${ }^{238} \mathrm{U},{ }^{234} \mathrm{Th},{ }^{234 \mathrm{~m}} \mathrm{~Pa}$ have the similar radioactivity. Absolute decay rate of ${ }^{238} \mathrm{U},{ }^{234} \mathrm{Th},{ }^{234 \mathrm{~m}} \mathrm{~Pa},{ }^{231} \mathrm{Th}$ and uranium concentration were determined in the samples analyzed with the use of the gamma-rays listed in the Table 3 . The decay data were taken from the ENSDF BNL-NCS-51655-01/02-Rev.

Three daughter nuclei of the equilibrium radioactive ${ }^{232} \mathrm{Th}$ decay chain $\left({ }^{228} \mathrm{Ac},{ }^{212} \mathrm{~Pb},{ }^{208} \mathrm{Tl}\right)$ were used for the determination of the natural radioactive and the spontaneous fission rates of the ${ }^{232} \mathrm{Th}$. The $\gamma$-ray energies and absolute $\gamma$-ray abundances of the ${ }^{228} \mathrm{Ac},{ }^{212} \mathrm{~Pb}$ and ${ }^{208} \mathrm{Tl}$ are listed in the Table 4 . The recommended decay data were taken from the ENSDF BNL-NCS-51655-01/02-Rev.

The concentration and natural radioactivity of potassium were measured with the use of the full absorption peak of the ${ }^{40} \mathrm{~K}$ at the $E_{\gamma}=1460.8 \mathrm{keV}$ in a gamma-ray spectrum of the samples analyzed. Nuclear data, the ${ }^{40} \mathrm{~K}$ decay scheme and the ${ }^{40} \mathrm{Ar}$ excited level scheme are given in Figure 1 and Figure 2, respectively.

The ${ }^{238} \mathrm{U},{ }^{235} \mathrm{U},{ }^{232} \mathrm{Th}$ and their daughter nuclei have low-level radioactivity in the samples analyzed, therefore the big cylindrical samples have been used to achieve large statistical reliability. Masses of the aluminum, titanium samples and glass of the photomultiplier were about $1800 \mathrm{~g}, 1871 \mathrm{~g}$, and $771 \mathrm{~g}$, respectively. The concentrations of the other trace, minor and major elements have been measured with the instrumental neutron activation analysis.

\section{Experimental Facility for Spectrometric Measurements}

Experimental facility includes gamma-ray spectrometer and a passive shielding of a HPGe detector. The passive shielding consists of $0.5 \mathrm{~mm}$ of copper, $1 \mathrm{~mm}$ of cadmium and $9 \mathrm{~cm}$ of lead with $2.8(4) \times 10^{-3} \mathrm{~s}^{-1}$ counting rate of ${ }^{210} \mathrm{~Pb}$ at the $46.5 \mathrm{keV}$. The usage of cadmium and copper as an inner layers of a multilayer shielding attenuates the bremsstrahlung and the $\mathrm{X}$-rays $(72.805 \mathrm{keV}$ abundance is $2.75 \%$ and $74.969 \mathrm{keV}$ abundance is $4.58 \%)$ induced by the beta-particles from the ${ }^{210} \mathrm{Bi}$ decay $\left(E_{\beta \max }=1.1621 \mathrm{MeV}\right)$ in the lead. A special effort was spent to reduce the background from the ${ }^{41} \mathrm{Ar}$ (counting rate is $1.3(2) \times 10^{-3} \mathrm{~s}^{-1}$ for the $1293.7 \mathrm{keV}$ peak at the reactor power of $17 \mathrm{MW}$ ). Therefore the distance between the detector and the copper layer of the passive shielding was reduced up to $3 \mathrm{~mm}$ (see Figure 3).

The integral background normalized to the mass of the Ge crystal in the energy range from $40 \mathrm{keV}$ to 2.7 $\mathrm{MeV}$ was determined to be $2.84 \mathrm{~s}^{-1} \cdot \mathrm{kg}^{-1}$. This value is by a factor of 2.2 worse than that obtained at the installation of the Felsenkeller laboratory at the ground level [16]. The shielding construction with the minimized gap of only $3 \mathrm{~mm}$ between detector and innermost copper increases the continuous background due to backscattering. However, in the energy range $100-150 \mathrm{keV}$ the reduction of the background by $3 \mathrm{~mm}$ gap exceeds the backscattering effect as long as the sample activity is lower than $3 \mathrm{~Bq}$, as it is shown in the Table 5 . A reference ${ }^{60} \mathrm{Co}$ gamma-ray source $(3.2 \mathrm{kBq})$ was used to investigate the influence of the backscattering effect during sample 
$S_{n} \quad 15641.2$

$S_{p} \quad 12528.2$

$S_{n} \quad 9869$
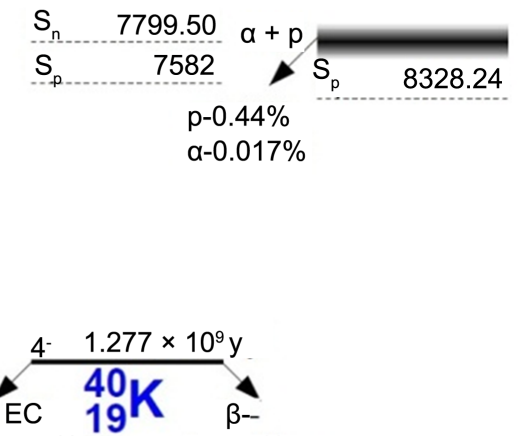

$10.72 \% \quad 89.28 \%$

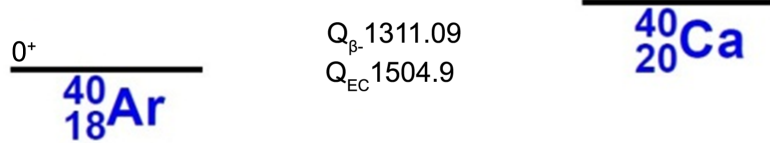

Figure 1 . The ${ }^{40} \mathrm{~K}$ decay scheme.

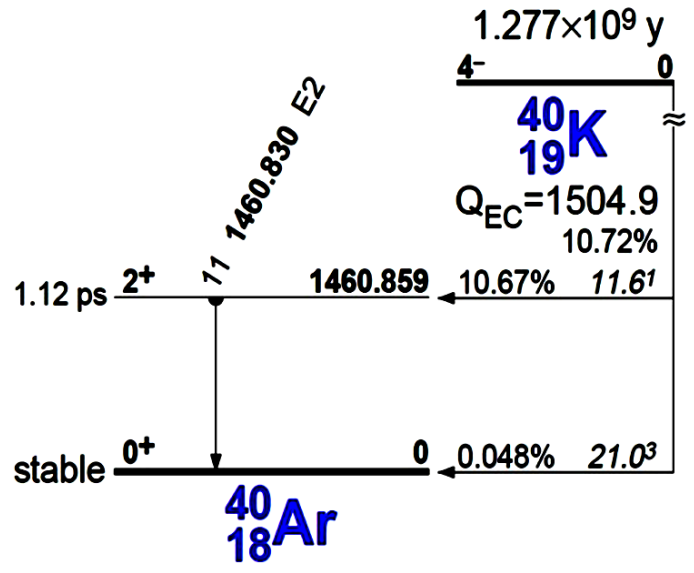

Figure 2. Excited level scheme of the ${ }^{40} \mathrm{Ar}$.

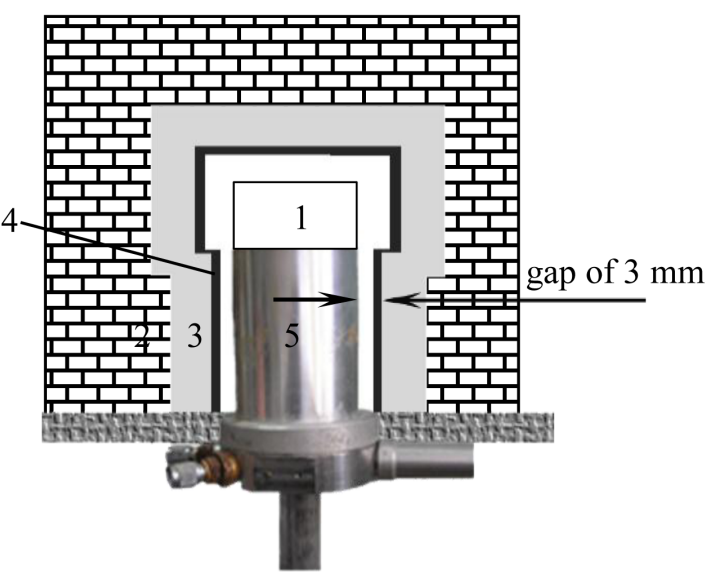

Figure 3. Schematic view of the shielding of the HPGe detector. 1-sample, 2-lead, 3-cadmium, 4-copper, 5-HPGe detector. 
Table 3. Main gamma-rays of the radioactive equilibrium ${ }^{238} \mathrm{U}$ and ${ }^{235} \mathrm{U}$ decay chains.

\begin{tabular}{cccc}
\hline Decay chain & Analytical isotope & $\begin{array}{c}\text { Gamma-ray } \\
\text { energy(keV) }\end{array}$ & $\begin{array}{c}\text { Absolute emission } \\
\text { intensity (\%) }\end{array}$ \\
\hline & ${ }^{234} \mathrm{Th}$ & $63.29(2)$ & $4.4(9)$ \\
${ }^{238} \mathrm{U}$ & ${ }^{234 \mathrm{~m}} \mathrm{~Pa}$ & $766.36(2)$ & $0.207(30)$ \\
& ${ }^{234 \mathrm{~m}} \mathrm{~Pa}$ & $1001.03(3)$ & $0.59(8)$ \\
& ${ }^{234} \mathrm{U}$ & $53.20(2)$ & $0.123(2)$ \\
& ${ }^{235} \mathrm{U}$ & $185.715(5)$ & $57.2(8)$ \\
${ }^{235} \mathrm{U}$ & ${ }^{231} \mathrm{Th}$ & $84,214(3)$ & $6.71(10)$ \\
\hline
\end{tabular}

Table 4. Main gamma-rays of the radioactive equilibrium ${ }^{232}$ Th decay chain.

\begin{tabular}{ccc}
\hline Isotope & Energy(keV) & Absolute emissionintensity (\%) \\
${ }^{212} \mathrm{~Pb}$ & $238.625(6)$ & $43.4(3)$ \\
${ }^{212} \mathrm{~Pb}$ & $300.09(1)$ & $3.3(1)$ \\
${ }^{228} \mathrm{Ac}$ & $338.322(2)$ & $11.25(3)$ \\
${ }^{208} \mathrm{Tl}$ & $583.191(2)$ & $84.4(7)$ \\
${ }^{228} \mathrm{Ac}$ & $911.205(4)$ & $26.6(7)$ \\
${ }^{228} \mathrm{Ac}$ & $968.971(10)$ & $16.1(3)$ \\
${ }^{228} \mathrm{Ac}$ & $1588.210(30)$ & $3.27(10)$ \\
${ }^{208} \mathrm{Tl}$ & $2614.532(13)$ & $99.9(4)$ \\
\hline
\end{tabular}

Table 5. Effect of the detector-shielding distance $L$ to the counting rate $I$ of the detector in the energy range from $100 \mathrm{keV}$ to $150 \mathrm{keV}$.

\begin{tabular}{|c|c|c|}
\hline \multirow{2}{*}{$L,(\mathrm{~mm})$} & \multicolumn{2}{|c|}{$I,\left(\mathrm{~s}^{-1}\right)$} \\
\hline & With ${ }^{60} \mathrm{Co}(3.2 \mathrm{kBq})$ & Without ${ }^{60} \mathrm{Co}$ \\
\hline 3 & 38.3 & 0.30 \\
\hline 50 & 36.0 & 0.33 \\
\hline
\end{tabular}

measurements. The energy range 100 - $150 \mathrm{keV}$ is just above the $\mathrm{K} \mathrm{X}$-ray absorption edge of the multilayer $\mathrm{Pb}-\mathrm{Cd}-\mathrm{Cu}$ shielding because these elements have corresponding edges at the energies of $87.95 \mathrm{keV}, 26.712 \mathrm{keV}$ and $8.982 \mathrm{keV}$.

The decision threshold $g$ in units of activity was determined using the full absorption peak at the signific-ance level $\alpha=0.025 \quad(P=97.5 \%)$,

$$
g=\frac{1.92}{\varepsilon P_{\gamma} t}\left(1+\sqrt{1+2.08 R_{0} t}\right)
$$

where $\varepsilon$ is the full energy peak registration efficiency for the sample-detector geometry, $P_{\gamma}$ is the gammaray emission probability, $t$ is the measurement time and $R_{0}$ is the count rate in seconds both in a region of 2.5 FWHM beyond the peak. Shown in Figure 4 is the energy dependence of the counting detector efficiency for the size of reference gamma-ray source (62 mm in diameter, $100 \mathrm{~mm}$ height). The crystalline hydrate of uranyl nitrate $\mathrm{UO}_{2}\left(\mathrm{NO}_{3}\right)_{2} \cdot 6 \mathrm{H}_{2} \mathrm{O}(750 \mathrm{~g})$ was taken as the reference gamma-ray source.

Figure 5 shows the energy dependence of the decision threshold $g$ under the assumption of $P_{\gamma}=1$ and $t=1$ day for the sample geometry (diameter $62 \mathrm{~mm}$, height $100 \mathrm{~mm}$ ) used in routine analyses for the determination of the sample natural radiation background. The decision threshold $g$ achieves minimum (see Figure 5) 


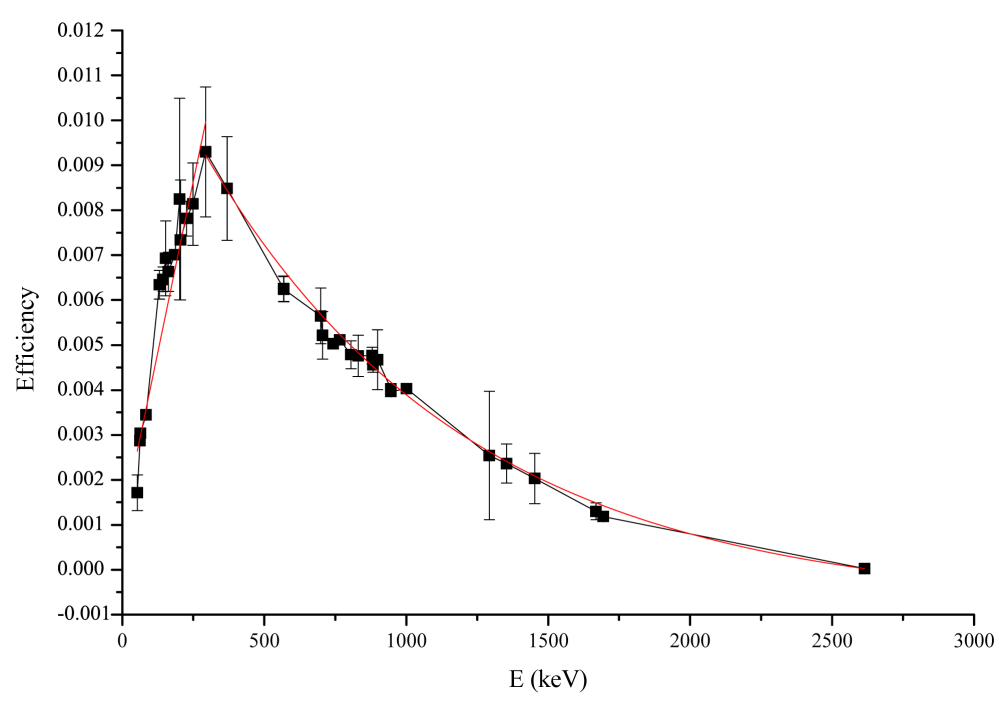

Figure 4. The efficiency calibration curve of the GC2018 HPGe detector.

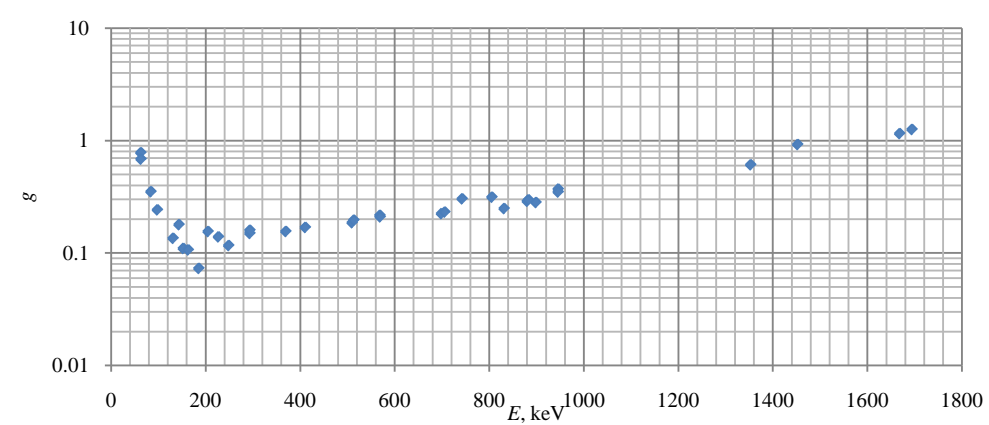

Figure 5. Decision threshold $g$ versus the energy for measurement time of 1 day and the normalized emission probability of $P_{\gamma}=1$.

at energies of approximately $200 \mathrm{keV}$, where the counting detector efficiency is maximum (Figure 4).

The decision threshold $R_{n}^{*}$ and the detection limit $R_{n}^{\#}$ in the units of counting rate at the selected energy were calculated as

$$
R_{n}^{*}=\frac{k_{1-\alpha}^{2}}{2 t} \frac{b}{2 l} \sqrt{1+\frac{4 N_{0}}{k_{1-\alpha}^{2}} \frac{2 l}{b}}\left(1+\frac{2 l}{b}\right)
$$

and

$$
R_{n}^{\#}=\left(k_{1-\alpha}+k_{1-\beta}\right) \sqrt{\frac{N_{0}}{t^{2}}\left(1+\frac{b}{2 l}\right)}+\frac{1}{4 t}\left(k_{1-\alpha}+k_{1-\beta}\right)^{2}\left(1+\frac{b}{2 l}\right)
$$

respectively [17]. The $k_{1-\alpha}$ and $k_{1-\beta}$ are the quantiles of the normal distribution for the error probability $\alpha$ of the type I and for the error probability $\beta$ of the type II, respectively ( $\alpha=\beta=0.025, P=97.5 \%$, $\left.k_{0.975}=1.96\right), N_{0}$ is the number of counts below the full absorption peak in the spectrum, the $l$ is full width at half maximum (FWHM) of the full absorption peak, the $b=2 l$ is the width of the full absorption peak, the $t$ is measurement time in the Equations (2) and (3). The energy dependences of $R_{n}^{*}$ and $R_{n}^{\#}$ are shown in the Figure 6.

The area uncertainty of the full absorption peak is then calculated as [17]

$$
U\left(N_{n}\right)=\sqrt{N_{B}+N_{0} \frac{b}{2 l}},
$$


where $N_{n}$ is the area of the full absorption peak and $N_{b}=N_{n}+N_{0}$. Figure 7 shows the energy dependence of the area uncertainty (\%) for measurement time of $t=1$ day, and sample of size $\varnothing 62 \mathrm{~mm}$, height $100 \mathrm{~mm}$.

The Table 6 presents, for example, decision threshold $g$ expressed in terms of activities for ${ }^{235} \mathrm{U},{ }^{234} \mathrm{~Pa}$ and ${ }^{208} \mathrm{Tl}$ containing in the natural aluminum sample. The required decision threshold $g$ for the aluminum sample can be reached at the measurement time of $7 \mathrm{~d}$ and the sample mass of $1.8 \mathrm{~kg}$.

The gamma-ray spectra of samples analyzed and large standard reference gamma-ray-emitting sources were measured with the coaxial p-type HPGe-detector of 20\% relative efficiency (CANBERRA GC2018) coupled

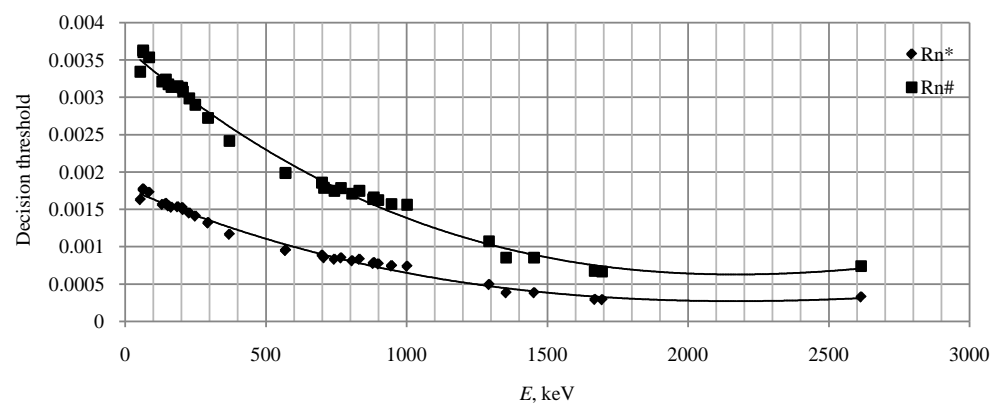

Figure 6. The energy dependence of $R_{n}^{*}$ and $R_{n}^{\#}$ of GC2018 HPGe detector for measurement time $t=1$ day and for the sample geometry of $\varnothing 62 \mathrm{~mm}$, height $100 \mathrm{~mm}$.

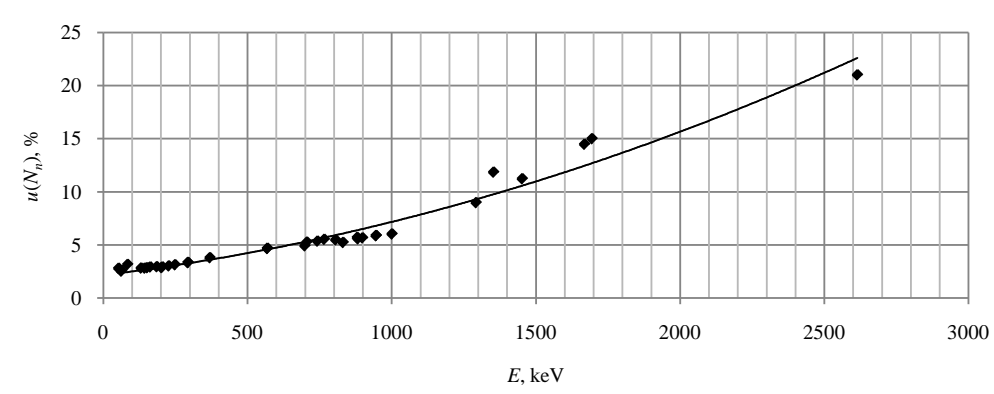

Figure 7. The area uncertainty (\%) versus the energy of the full absorption peak at the measurement time of $t=1 \mathrm{~d}$, and sample geometry of $\varnothing 62 \mathrm{~mm}$, height $100 \mathrm{~mm}$.

Table 6. The decision thresholds $g$ for ${ }^{235} \mathrm{U},{ }^{234} \mathrm{~Pa}$ and ${ }^{208} \mathrm{Tl}$ for the aluminum sample at the relative detector efficiency of $20 \%$, the measurement time of $7 \mathrm{~d}$ and the sample mass of $1.8 \mathrm{~kg}$.

\begin{tabular}{ccccc}
\hline Nuclide & $P_{\gamma}$ & $\varepsilon$ & $E(\mathrm{keV})$ & $g(\mathrm{~Bq})$ \\
\hline${ }^{235} \mathrm{U}$ & 10.960 & 0.00646 & 143.75 & 0.178 \\
${ }^{235} \mathrm{U}$ & 5.080 & 0.00663 & 163.33 & 0.250 \\
${ }^{235} \mathrm{U}$ & 57.200 & 0.00701 & 185.68 & 0.073 \\
${ }^{235} \mathrm{U}$ & 5.010 & 0.00734 & 205.27 & 0.225 \\
${ }^{234} \mathrm{~Pa}$ & 20.000 & 0.00634 & 131.2 & 0.135 \\
${ }^{234} \mathrm{~Pa}$ & 11.400 & 0.00781 & 227.2 & 0.139 \\
${ }^{234} \mathrm{~Pa}$ & 10.200 & 0.00624 & 569.5 & 0.149 \\
${ }^{234} \mathrm{~Pa}$ & 15.000 & 0.00456 & 883.24 & 0.154 \\
${ }^{234} \mathrm{~Pa}$ & 12.000 & 0.00403 & 946 & 0.190 \\
${ }^{208} \mathrm{Tl}$ & 99.830 & 0.0000243 & 2614.82 & 7.988 \\
\hline
\end{tabular}


with "Lynx" multichannel digital analyzer (Canberra, USA). The germanium crystal of the detector has a diameter of $62 \mathrm{~mm}$ and a length of $30 \mathrm{~mm}$, which is equivalent to a volume and mass of the active germanium of $90.6 \mathrm{~cm}^{3}$ and $0.482 \mathrm{~kg}$, respectively. The FWHM of the detector at the energy of $1.332 \mathrm{MeV}$ was determined to be $1.7 \mathrm{keV}$.

\section{Experiment}

The concentration and specific radioactivity of potassium, uranium, thorium and their daughter nuclei were measured with the gamma spectrometric method. The concentrations of As, Ce, Co, Cr, Fe, Hf, La, Na, Sb, Sc, $\mathrm{Sm}, \mathrm{Th}, \mathrm{U}, \mathrm{Zn}$ have been measured with the instrumental neutron activation analysis.

1) Relative gamma spectrometric technique

The relative gamma spectrometric technique was used to measure the absolute decay rate and the spontaneous fission rate of the natural radioactive elements in samples analyzed. Here the specific activity $S A_{s}$ of a radioisotope is obtained by direct comparison with the activity $A_{s t}$ of the same radionuclide given in a reference gamma-ray-emitting-source by the following equation [18]

$$
S A_{s m}=\frac{A_{s t}}{m_{s m}} \cdot \frac{S_{s m} t_{s t}}{S_{s t} t_{s m}} \cdot \frac{\mu_{s t}(E)}{\mu_{s m}(E)}
$$

where the subscripts $s m$ and $s t$ mark the value belonging to the sample and the reference source, respectively, the $m_{s m}$ is sample mass and $S$ is the area of the full absorption peak. The $t$ is measurement time of a gamma-ray spectrum. The $\mu_{s m}$ and $\mu_{\text {st }}$ are gamma-ray transmission coefficients of the sample and reference source materials, respectively. The energy dependence of the gamma-ray transmission coefficient assuming $a=R$ can be calculated according to expression

$$
\mu(E)=\frac{1}{\pi l a^{2}} \int_{h_{0}}^{h_{0}+l} \mathrm{~d} h \int_{0}^{a} \rho \mathrm{d} \rho \int_{-\frac{\pi}{2}}^{\frac{\pi}{2}} \mathrm{~d} \varphi\left(\int_{0}^{\theta_{1}} \mathrm{e}^{\frac{-\tau(E) \cdot\left(h-h_{0}\right)}{\cos \theta}} \sin \theta \mathrm{d} \theta\right)
$$

where $\tau(E)$ is the total linear absorption factor of the sample or reference source, respectively. Figure 8 shows the registration geometry of the gamma-ray with the Ge detector. The $x$ and $y$ are distances travelled by $\gamma$-ray through the detector and the sample, respectively, the $a$ and $R$ are the detector and the sample radii, respectively, the $b$ and $l$ are the detector and the sample heights, respectively, the $h_{0}$ is the detector-sample distance in Figure 8 and in Equation (6).

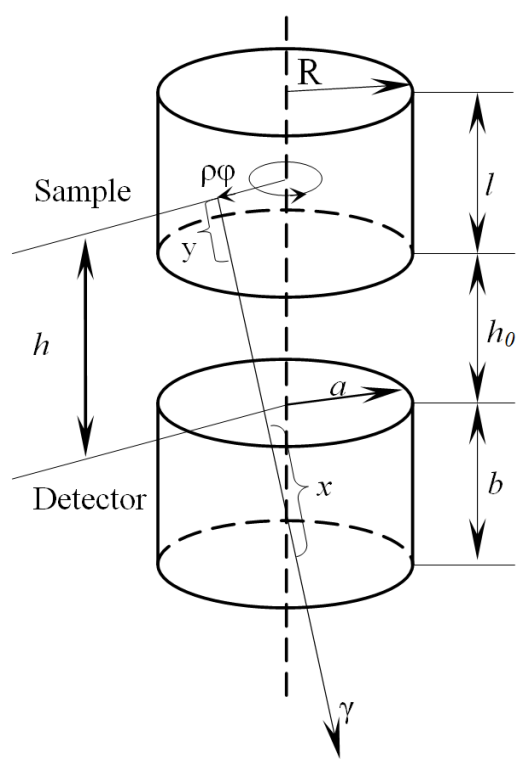

Figure 8. Gamma-ray registration geometry for a large sample with HPGe detector. 
Given in the Figure 9 are the energy dependences of the gamma-ray transmission coefficient for the $\mathrm{Al}, \mathrm{Ti}$, $\mathrm{KBr}$, the $\mathrm{UO}_{2}\left(\mathrm{NO}_{3}\right)_{2} \cdot 6 \mathrm{H}_{2} \mathrm{O}$ and quartz glass samples of size $R=3.1 \mathrm{~cm}, l=10 \mathrm{~cm}$ used in the routine analyses for the determination of radioactivity of the natural radioactive elements.

To carry out measurements the reference gamma-ray-emitting-sources of ${ }^{40} \mathrm{~K},{ }^{228} \mathrm{Th},{ }^{238} \mathrm{U},{ }^{235} \mathrm{U},{ }^{234} \mathrm{U}$ and their daughter nuclei with the accurately known the absolute decay rates were prepared. The $\mathrm{UO}_{2}\left(\mathrm{NO}_{3}\right)_{2} \cdot 6 \mathrm{H}_{2} \mathrm{O}$ $\left(m=750 \mathrm{~g}, \rho=2.807 \mathrm{~g} \cdot \mathrm{cm}^{-3}\right)$ and $\mathrm{KBr}\left(m=500 \mathrm{~g}, \rho=2.75 \mathrm{~g} \cdot \mathrm{cm}^{-3}\right)$ were taken as large calibration gamma-ray sources. The reference data were taken from the LNHB (available at

http://www.nucleide.org/NucData.htm) and are presented in the Table 7.

The samples analyzed and the standard reference gamma-ray-emitting-sources had the same sizes. For measurement the time period were taken from 7 to 32 days. The full absorption ${ }^{208} \mathrm{Tl} 510.77 \mathrm{keV}, 583.19 \mathrm{keV},{ }^{40} \mathrm{~K}$ $1460.82 \mathrm{keV}$ and ${ }^{214} \mathrm{Bi} 1729.59 \mathrm{keV}, 1764.5 \mathrm{keV}$ peaks registered in the gamma-ray spectra of the samples analyzed given in Figures 10-12.

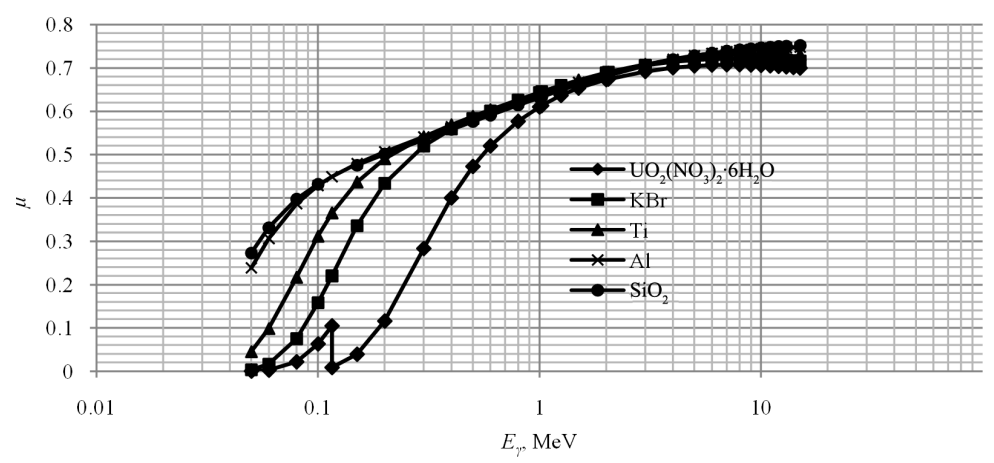

Figure 9. The energy dependences of the gamma-ray transmission coefficient for the $\mathrm{Al}$, Ti, $\mathrm{KBr}$, the $\mathrm{UO}_{2}\left(\mathrm{NO}_{3}\right)_{2} \cdot 6 \mathrm{H}_{2} \mathrm{O}$ and quartz glass samples for $R=$ $3.1 \mathrm{~cm}, l=10 \mathrm{~cm}$.

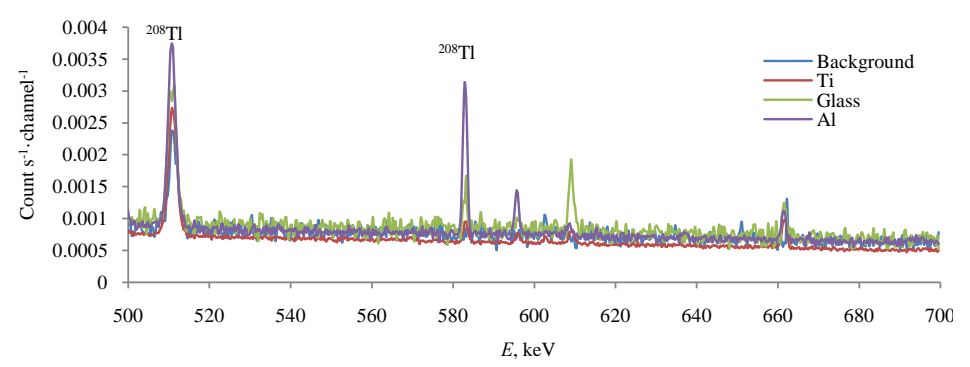

Figure 10. The full absorption ${ }^{208} \mathrm{Tl}$ peaks $510.77 \mathrm{keV}, 583.19 \mathrm{keV}$ in the radioactive equilibrium ${ }^{232} \mathrm{Th}$ decay chain registered in the gamma-ray spectra of the samples analyzed.

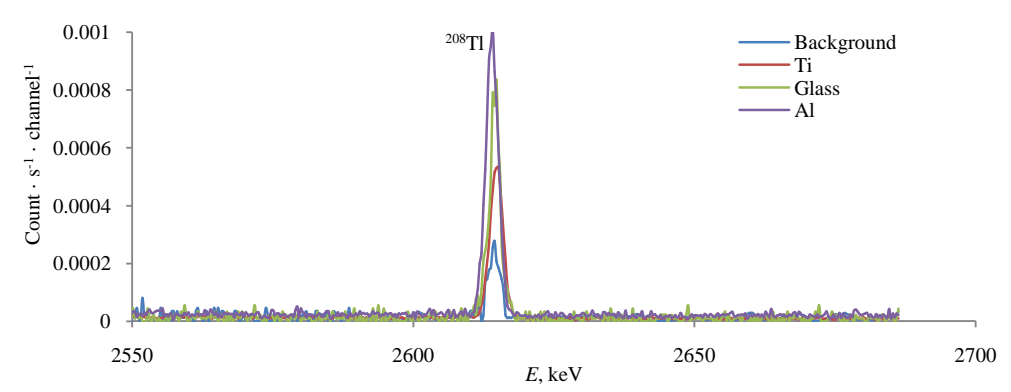

Figure 11. The full absorption ${ }^{208} \mathrm{Tl}$ peak $2614.55 \mathrm{keV}$ in the radioactive equilibrium ${ }^{232}$ Th decay chain registered in the gamma-ray spectra of the samples analyzed. 


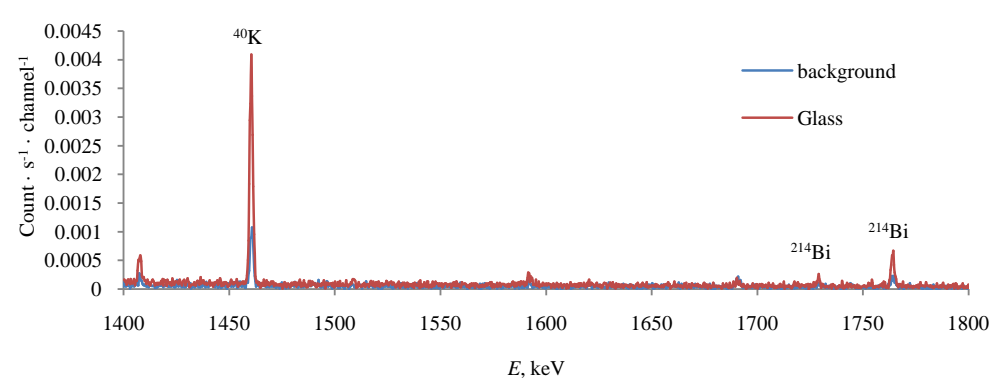

Figure 12. The full absorption ${ }^{40} \mathrm{~K} 1460.82 \mathrm{keV}$ and ${ }^{214} \mathrm{Bi} 1729.59 \mathrm{keV}, 1764.5$ $\mathrm{keV}$ peaks registered in the gamma-ray spectra of the samples analyzed.

Table 7. Characteristics of the standard reference gamma-ray-emitting sources.

\begin{tabular}{|c|c|c|c|c|c|c|}
\hline Material & Isotope & $T_{1 / 2}$ & $\begin{array}{l}\text { Absolute decay } \\
\text { rate (Bk) }\end{array}$ & $\begin{array}{l}\text { Decay } \\
\text { mode }\end{array}$ & $\begin{array}{l}\text { Particle energy } \\
\quad(\mathrm{keV})\end{array}$ & $\begin{array}{c}\text { Particle emission } \\
\text { intensity (\%) }\end{array}$ \\
\hline \multirow[t]{16}{*}{$\mathrm{UO}_{2}\left(\mathrm{NO}_{3}\right)_{2} \cdot 6 \mathrm{H}_{2} \mathrm{O}$} & ${ }^{238} \mathrm{U}$ & $4.468(5) \times 10^{9} y$ & $4.3(3) \times 10^{6}$ & $\alpha$ & 4198 & $77.5(5)$ \\
\hline & & & & & 4151 & $22.3(5)$ \\
\hline & & & & & 4038 & $0.13(3)$ \\
\hline & ${ }^{235} \mathrm{U}$ & $7.04(1) \times 10^{8} y$ & $69.9(2) \times 10^{3}$ & $\alpha$ & 4397.8 & $57.19(20)$ \\
\hline & & & & & 4366.1 & $18.30(13)$ \\
\hline & & & & & 4214.7 & $5.95(12)$ \\
\hline & & & & & 4596.4 & $4.74(6)$ \\
\hline & & & & & 4556.0 & $3.79(6)$ \\
\hline & & & & & 4322 & $3.33(6)$ \\
\hline & & & & & 4414.9 & $3.01(16)$ \\
\hline & & & & & 4502.4 & $1.28(5)$ \\
\hline & ${ }^{234} \mathrm{U}$ & $2.455(6) \cdot 10^{5} \mathrm{y}$ & $522(2) \times 0^{3}$ & $\alpha$ & 4774.6 & $71.37(2)$ \\
\hline & & & & & 4722.4 & $28.42(2)$ \\
\hline & & & & & 4603.5 & $0.210(2)$ \\
\hline & ${ }^{228} \mathrm{Th}$ & $1.9126(9) \mathrm{y}$ & $1.70(8) \times 10^{3}$ & $\alpha$ & 5423.24(22) & $74.0(6)$ \\
\hline & & & & & $5340.35(22)$ & $26.0(8)$ \\
\hline \multirow[t]{2}{*}{$\mathrm{KBr}$} & ${ }^{40} \mathrm{~K}$ & $1.407(7) \times 10^{9} y$ & $5.7(2) \times 10^{3}$ & $\beta^{-}$ & 1311.09 & 89.25(17) \\
\hline & & $11.90(11) \times 10^{9} \mathrm{y}$ & & EC & 1504.9 & $10.55(11)$ \\
\hline
\end{tabular}

The decay data were taken from the LNHB (available at http://www.nucleide.org/NucData.htm).

\section{2) Instrumental neutron activation analysis technique}

Instrumental neutron activation analysis technique was used to measure the concentrations of 14 trace elements in the samples. The aluminum, titanium, glass samples and comparison standard (IAEA 433 standard reference material) were packed in high-purity quartz glass ampoules. The sample and the comparison standard mass were about 30 - $50 \mathrm{mg}$. The samples and comparison standard were irradiated in a water channel of the WWR-M reactor for two hours at thermal $f_{t h}=6.3 \times 10^{13} \mathrm{~s}^{-1} \cdot \mathrm{cm}^{-2}$ and epithermal $f_{\text {epi }}=3.1 \times 10^{12} \mathrm{~s}^{-1} \cdot \mathrm{cm}^{-2}$ neutron fluxes. After irradiation the ampoules were washed out with the $0.5 \mathrm{M} \mathrm{HNO}_{3}$ aqueous solution and the distilled water. The total sample and the comparison standard was measured with the $20 \%$ coaxial HPGe detector (Canberra, FWHM $1.7 \mathrm{keV}$ at $E_{\gamma}=1332.5 \mathrm{keV}$ ). The gamma ray spectra were measured after 3, 6 and 20 days of cooling time. The analysis results of the sample and the nuclear characteristics [15] of the nuclides used to determine the concentrations are shown in the Table 8. 
Equation (7) shows the time dependence of the daughter nucleus amount for an equilibrium ${ }^{238} \mathrm{U}$ decay chain:

$$
N_{n}=\lambda_{1} \cdot \lambda_{2} \cdots \lambda_{n-1} N_{1,0}\left(\frac{\mathrm{e}^{-\lambda_{1} t}}{\left(\lambda_{2}-\lambda_{1}\right) \cdot\left(\lambda_{3}-\lambda_{1}\right) \cdots\left(\lambda_{n}-\lambda_{1}\right)}+\cdots+\frac{\mathrm{e}^{-\lambda_{n} t}}{\left(\lambda_{1}-\lambda_{n}\right) \cdot\left(\lambda_{2}-\lambda_{n}\right) \cdots\left(\lambda_{n-1}-\lambda_{n}\right)}\right)
$$

where the $N_{1,0}=\frac{m_{s m} \cdot C_{U} \cdot a \cdot N_{A}}{100 \cdot A W}$ is the number of the uranium nuclei in the samples analyzed, the $\lambda$ is decay constant, the $N_{A}$ is Avogadro number, the $A W$ is atomic weight, the $a$ is the isotopic abundance, the $m_{s m}$ is sample mass. $C_{U}$ is the mass concentration (\%) of uranium in the sample that was measured with the instrumental neutron activation analysis. The time period when the activity of the daughter nuclei reaches a maximum was calculated with the equation $t_{m}=\frac{\ln \left(\lambda_{2} / \lambda_{1}\right)}{\lambda_{2}-\lambda_{1}}$. The activity of the daughter nucleus is $A_{i}=\lambda_{i} N_{i}$ at any time $t$ with the initial condition $N_{i}=0$ at $t=0$. In our case the time $t$ is equal to $t_{m}$.

\section{Discussion}

Natural uranium contains $99.274 \%$ of ${ }^{238} U, 0.720 \%$ of ${ }^{235} \mathrm{U}$, and $0.0055 \%$ of radiogenic ${ }^{234} \mathrm{U}$. The ${ }^{238} \mathrm{U},{ }^{235} \mathrm{U}$ and ${ }^{234} \mathrm{U}$ decay via alpha emission to ${ }^{234} \mathrm{Th},{ }^{231} \mathrm{Th}$ and ${ }^{230} \mathrm{Th}$, respectively. The alpha decay energies $Q_{\alpha}$ of the ${ }^{234} \mathrm{U}$, ${ }^{235} \mathrm{U}$, ${ }^{238} \mathrm{U}$ are equal to $4858.5,4678.7$, and $4270 \mathrm{keV}$ [7], respectively. The total radioactivity of the natural uranium connected with ${ }^{238} \mathrm{U}$ and ${ }^{234} \mathrm{U}$ for the aluminum, titanium and glass samples shown in the Table 9 can be divided half-and-half between ${ }^{234} \mathrm{U}$ and ${ }^{238} \mathrm{U}$, as the ${ }^{235} \mathrm{U}$ contribution to the radioactivity of the natural uranium can be neglected. The ${ }^{238} \mathrm{U}$ absolute decay rate is more than ${ }^{235} \mathrm{U}$ rate by the factor of 15.1(30) and 30(12) in the aluminum and glass samples, respectively.

The natural radioactivity and spontaneous fission rates of the ${ }^{238} \mathrm{U},{ }^{235} \mathrm{U},{ }^{234} \mathrm{U},{ }^{232} \mathrm{Th}$ and their daughter nuclei were measured with the relative gamma spectrometric technique and were calculated using the INAA data according to Equation (7). In the Table 9 the radioactivities measured $A_{\text {meas }}$, calculated $A_{\text {calc }}$ and spontaneous fission rates $I$ for these radionuclides are listed. Radioactivity of ${ }^{238} \mathrm{U}$ was calculated to be the average of the measured ${ }^{234} \mathrm{Th}$ and ${ }^{234 \mathrm{~m}} \mathrm{~Pa}$ activity values.

Table 8. Mass concentrations of elements determined measured with NAA technique in Al, Ti and glass samples.

\begin{tabular}{|c|c|c|c|c|c|c|c|}
\hline Element & Nuclide & $\begin{array}{c}E_{\gamma} \\
(\mathrm{keV})\end{array}$ & $\begin{array}{c}\gamma \text {-ray } \\
\text { abundance }\end{array}$ & $\begin{array}{l}T_{1 / 2} \\
\text { (d) }\end{array}$ & $\begin{array}{l}C_{A l} \\
(\%)\end{array}$ & $\begin{array}{l}C_{T i} \\
(\%)\end{array}$ & $\begin{array}{l}C_{\text {glass }} \\
(\%)\end{array}$ \\
\hline As & ${ }^{76} \mathrm{As}$ & 559.1 & 45 & 1.078 & & $1.9(1) \times 10^{-3}$ & \\
\hline $\mathrm{Ce}$ & ${ }^{141} \mathrm{Ce}$ & 145.44 & 48.29 & 32.5 & $2.3(3) \times 10^{-4}$ & & \\
\hline Co & ${ }^{60} \mathrm{Co}$ & 1332.49 & 99.98 & 1925 & $2.2(1) \times 10^{-4}$ & $7.2(8) \times 10^{-5}$ & \\
\hline $\mathrm{Cr}$ & ${ }^{51} \mathrm{Cr}$ & 320.08 & 9.91 & 27.7 & $2.31(2) \times 10^{-2}$ & $1.95(2) \times 10^{-2}$ & \\
\hline $\mathrm{Fe}$ & ${ }^{59} \mathrm{Fe}$ & 1099.25 & 56.5 & 44.5 & $2.2(2) \times 10^{-1}$ & $6.8(7) \times 10^{-2}$ & \\
\hline Hf & ${ }^{181} \mathrm{Hf}$ & 482.18 & 80.5 & 42.39 & $3.9(4) \times 10^{-5}$ & & \\
\hline $\mathrm{La}$ & ${ }^{140} \mathrm{La}$ & 1596.21 & 95.4 & 1.68 & $3.2(3) \times 10^{-4}$ & $1.6(4) \times 10^{-6}$ & \\
\hline $\mathrm{Na}$ & ${ }^{24} \mathrm{Na}$ & 1368.63 & 99.99 & 0.623 & $1.14(2) \times 10^{-2}$ & & \\
\hline $\mathrm{Sb}$ & ${ }^{124} \mathrm{Sb}$ & 602.73 & 97.79 & 60.2 & $1.5(6) \times 10^{-5}$ & $9.7(6) \times 10^{-5}$ & \\
\hline Sc & ${ }^{46} \mathrm{Sc}$ & 889.28 & 99.98 & 83.79 & $3.3(1) \times 10^{-5}$ & & \\
\hline $\mathrm{Sm}$ & ${ }^{153} \mathrm{Sm}$ & 103.18 & 29.25 & 1.928 & $9.7(8) \times 10^{-6}$ & & \\
\hline Th & ${ }^{233} \mathrm{Th}$ & 311.90 & 38.50 & 26.97 & $6.1(9) \times 10^{-4}$ & & \\
\hline $\mathrm{U}$ & ${ }^{239} \mathrm{U}$ & 106.12 & 26.3 & 2.357 & $3.1(6) \times 10^{-5}$ & $4.7(3) \times 10^{-6}$ & $7.3(7) \times 10^{-4}$ \\
\hline $\mathrm{Zn}$ & ${ }^{65} \mathrm{Zn}$ & 1115.54 & 50.6 & 244.3 & $4.66(9) \times 10^{-2}$ & & \\
\hline K & ${ }^{40} \mathrm{~K}$ & & & & & & $9.7(2) \times 10^{-2}$ \\
\hline
\end{tabular}


The ${ }^{238} \mathrm{U}$ half-life is $1.41 \times 10^{17}$ seconds, therefore $5.58 \times 10^{-4} \mathrm{~g}$ of the ${ }^{238} \mathrm{U}$ have absolute alpha decay rate of 6.8(9) $\mathrm{s}^{-1}$ and produce the same number of ${ }^{234} \mathrm{Th}$ nuclei in the aluminum sample $(1800 \mathrm{~g})$. The number of the daughter nuclei with the exception of the ${ }^{206} \mathrm{~Pb}$ is decreased with the time but the mass ratio of the daughter nuclei remains constant after the radioactive equilibrium is achieved. If absolute decay rate of ${ }^{238} \mathrm{U}$ is equal to 6.8(9) $\mathrm{Bq}$, then $5.58 \times 10^{-4} \mathrm{~g}$ of the ${ }^{238} \mathrm{U}$ enclose $2.07 \times 10^{7}$ nuclei $\left(7.97 \times 10^{-15} \mathrm{~g}\right)$ of ${ }^{234} \mathrm{Th}$ in the equilibrium radioactive ${ }^{238} \mathrm{U}$ decay chain inside the aluminum sample. Mass concentration of ${ }^{232} \mathrm{Th}$ was calculated according to Equation (9), where $a=0.3594$ is alpha decay branching of ${ }^{212} \mathrm{Bi}$, the $A_{s p}$ is specific radioactivity of ${ }^{208} \mathrm{Tl}$. Mass concentrations and specific activities of ${ }^{232} \mathrm{Th},{ }^{234} \mathrm{Th}$ and ${ }^{234 \mathrm{~m}} \mathrm{~Pa}$ in the samples analyzed are listed in the Table 10.

The ${ }^{230}$ Th does not have suitable analytical gamma lines for measuring its radioactivity. The radioactivity and neutron emission by spontaneous fission of ${ }^{230} \mathrm{Th}$ were not measured because ${ }^{238} \mathrm{U}$ does not go to radioactivity equilibrium with its daughter nucleus ${ }^{230} \mathrm{Th}$. The contribution of ${ }^{230} \mathrm{Th}$ in the neutron emission of the sample is negligible since the spontaneous fission probability per decay of ${ }^{230} \mathrm{Th}$ is less than $4 \times 10^{-12} \%$. The fast neutron radiation intensity normalized to the sample mass was calculated. The intensity values are given in the Table 11 .

\section{Conclusion}

In this work, the evaluation of the gamma and neutron emissions were performed for eight nuclides, from the natural radioactive ${ }^{238} \mathrm{U},{ }^{235} \mathrm{U}$ and ${ }^{232} \mathrm{Th}$ decay chains for aluminum, titanium and glass. The integral gamma radi-

Table 9. The natural radioactivity $A$ and spontaneous fission rate $I$ of ${ }^{238} \mathrm{U},{ }^{235} \mathrm{U},{ }^{234} \mathrm{U},{ }^{232} \mathrm{Th}$ and their daughter nuclei normalized to the sample mass.

\begin{tabular}{|c|c|c|c|c|c|c|c|c|c|c|c|}
\hline \multirow[b]{2}{*}{ Nuclide } & \multirow[b]{2}{*}{$T_{1 / 2}$} & \multirow{2}{*}{$\begin{array}{c}E_{\gamma} \\
(\mathrm{keV})\end{array}$} & \multirow{2}{*}{$\gamma_{a b n}(\%)$} & \multicolumn{3}{|c|}{$\mathrm{Al}$} & \multicolumn{3}{|c|}{ Glass } & \multicolumn{2}{|c|}{$\mathrm{Ti}$} \\
\hline & & & & $\begin{array}{c}A_{\text {calc }} \\
\left(\mathrm{Bk} \cdot \mathrm{g}^{-1}\right)\end{array}$ & $\begin{array}{c}A_{\text {meas }} \\
\left(\mathrm{Bk} \cdot \mathrm{g}^{-1}\right)\end{array}$ & $\begin{array}{c}I \\
\left(\mathrm{~s}^{-1} \mathrm{~g}^{-1}\right)\end{array}$ & $\begin{array}{c}A_{\text {calc }} \\
\left(\mathrm{Bk} \cdot \mathrm{g}^{-1}\right)\end{array}$ & $\begin{array}{c}A_{\text {meas }} \\
\left(\mathrm{Bk} \cdot \mathrm{g}^{-1}\right)\end{array}$ & $\begin{array}{c}I \\
\left(\mathrm{~s}^{-1} \cdot \mathrm{g}^{-1}\right)\end{array}$ & $\begin{array}{c}A_{\text {meas }} \\
\left(\mathrm{Bk} \cdot \mathrm{g}^{-1}\right)\end{array}$ & $\begin{array}{c}I \\
\left(\mathrm{~s}^{-1} \cdot \mathrm{g}^{-1}\right)\end{array}$ \\
\hline${ }^{238} \mathrm{U}$ & $4.468 \times 10^{9} \mathrm{y}$ & & & $3.8(7) \times 10^{-3}$ & $* 6.8(9) \times 10^{-3}$ & $3.7(5) \times 10^{-9}$ & $8.9(9) \times 10^{-3}$ & ${ }^{*} 1.1(4) \times 10^{-2}$ & $6(2) \times 10^{-9}$ & ${ }^{*} 5.8(3) \times 10^{-4}$ & $3.1(2) \times 10^{-10}$ \\
\hline${ }^{234} \mathrm{Th}$ & $24.1 \mathrm{~d}$ & $\begin{array}{c}63.3 \\
92.59 \\
112.85\end{array}$ & $\begin{array}{c}4.47 \\
2.562 \\
0.2562\end{array}$ & $3.8(7) \times 10^{-3}$ & $5.9(15) \times 10^{-3}$ & & $9.0(9) \times 10^{-3}$ & $8.2(2) \times 10^{-3}$ & & $6.5(2) \times 10^{-4}$ & \\
\hline${ }^{234 \mathrm{~m}} \mathrm{~Pa}$ & $1.17 \mathrm{~min}$ & $\begin{array}{l}766.6 \\
1001\end{array}$ & $\begin{array}{l}0.207 \\
0.589\end{array}$ & $3.8(7) \times 10^{-3}$ & $7.7(2) \times 10^{-3}$ & $<7.7 \times 10^{-14}$ & $9.0(9) \times 10^{-3}$ & $1.4(4) \times 10^{-2}$ & $<1.4 \times 10^{-13}$ & $5.0(4) \times 10^{-4}$ & $<5 \times 10^{-15}$ \\
\hline${ }^{234} \mathrm{~Pa}$ & $6.70 \mathrm{~h}$ & $\begin{array}{l}131.2 \\
926.7 \\
880.5\end{array}$ & $\begin{array}{c}20 \\
22 \\
4\end{array}$ & $6.2(9) \times 10^{-6}$ & $5.3(4) \times 10^{-6}$ & $<1.6 \times 10^{-17}$ & $1.4(1) \times 10^{-5}$ & $1.9(6) \times 10^{-5}$ & $<5.7 \times 10^{-17}$ & Not found & \\
\hline${ }^{234} \mathrm{U}$ & $2.455 \times 10^{5} \mathrm{y}$ & 53.2 & 2.2 & $1.6(3) \times 10^{-3}$ & $6.5(14) \times 10^{-3}$ & $1.1(3) \times 10^{-13}$ & $3.6(4) \times 10^{-3}$ & $7.6(7) \times 10^{-3}$ & $1.2(3) \times 10^{-13}$ & 3 Not found & \\
\hline${ }^{230} \mathrm{Th}$ & $7.538 \times 10^{4} \mathrm{y}$ & & & & & & & & & & \\
\hline $\begin{array}{l}{ }^{232} \mathrm{Th} \\
\left({ }^{208} \mathrm{Tl}\right)\end{array}$ & $1.405 \times 10^{10} \mathrm{y}$ & $\begin{array}{r}2614.9 \\
583.25 \\
510.89\end{array}$ & $\begin{array}{l}99.16 \\
85.1 \\
22.8\end{array}$ & & $3.7(11) \times 10^{-2}$ & $4.1(12) \times 10^{-13}$ & & $1.32(5) \times 10^{-3}$ & $1.5(1) \times 10^{-14}$ & ${ }^{4} 9.1(4) \times 10^{-6}$ & $1.0(1) \times 10^{-16}$ \\
\hline${ }^{235} \mathrm{U}$ & $7.038 \times 10^{8} \mathrm{y}$ & 185.7 & 54 & $1.8(3) \times 10^{-4}$ & $4.5(3) \times 10^{-4}$ & $3.2(3) \times 10^{-14}$ & $4.1(4) \times 10^{-4}$ & $3.7(1) \times 10^{-4}$ & $2.6(2) \times 10^{-14}$ & ${ }^{4} 7.2(2) \times 10^{-5}$ & $5.1(3) \times 10^{-15}$ \\
\hline${ }^{40} \mathrm{~K}$ & $1.277 \times 10^{9} \mathrm{y}$ & 1460.8 & 10.67 & & - & & & $13.2(3) \times 10^{-2}$ & & - & \\
\hline
\end{tabular}

The asterisk ${ }^{*}$ marks the average of the measured ${ }^{234} \mathrm{Th}$ and ${ }^{234 \mathrm{~m}} \mathrm{~Pa}$ activity values because they are daughter nuclei of the natural equilibrium radioactive ${ }^{238} \mathrm{U}$ decay chain. $\gamma_{a b n}-\gamma$-ray abundance.

Table 10. The specific activity and content of ${ }^{232} \mathrm{Th},{ }^{234} \mathrm{Th}$ and ${ }^{234 \mathrm{~m}} \mathrm{~Pa}$ in the samples analysed.

\begin{tabular}{ccccccc}
\hline \multirow{2}{*}{ Sample } & \multicolumn{3}{c}{$A_{\text {sp }}\left(\mathrm{Bq} \mathrm{g}^{-1}\right)$} & & \multicolumn{2}{c}{$C(\%)$} \\
\cline { 2 - 7 } & ${ }^{232} \mathrm{Th}$ & ${ }^{234} \mathrm{Th}$ & ${ }^{234 \mathrm{~m}} \mathrm{~Pa}$ & ${ }^{232} \mathrm{Th}$ & ${ }^{234} \mathrm{Th}$ & ${ }^{234 \mathrm{~m}} \mathrm{~Pa}$ \\
\hline Al & $3.7(11) \times 10^{-2}$ & $5.9(15) \times 10^{-3}$ & $7.7(2) \times 10^{-3}$ & $2.5(8) \times 10^{-3}$ & $6.8(17) \times 10^{-16}$ & $5.0(2) \times 10^{-22}$ \\
$\mathrm{Ti}$ & $9.1(4) \times 10^{-6}$ & $6.5(2) \times 10^{-4}$ & $5.0(4) \times 10^{-4}$ & $6.2(3) \times 10^{-7}$ & $7.5(3) \times 10^{-17}$ & $3.2(3) \times 10^{-23}$ \\
Glass & $1.32(5) \times 10^{-3}$ & $8.2(2) \times 10^{-3}$ & $1.4(4) \times 10^{-2}$ & $9.1(3) \times 10^{-5}$ & $9.5(3) \times 10^{-16}$ & $9.1(26) \times 10^{-22}$ \\
\hline
\end{tabular}


Table 11. Neutron radiation intensity normalized to the sample mass.

\begin{tabular}{|c|c|c|c|c|c|c|c|c|}
\hline \multirow{2}{*}{ Decay chain } & \multirow{2}{*}{ Nuclide } & \multirow{2}{*}{$T_{1 / 2}$} & \multirow{2}{*}{$T_{1 / 2(\mathrm{SF})}$} & \multirow{2}{*}{$S F(\%)$} & \multirow{2}{*}{$n_{A b n}$} & \multicolumn{3}{|c|}{$F_{\text {fast }} \mathrm{s}^{-1} \cdot \mathrm{kg}^{-1}$} \\
\hline & & & & & & $\mathrm{Al}$ & Glass & $\mathrm{Ti}$ \\
\hline \multirow[t]{6}{*}{${ }^{238} \mathrm{U}$} & ${ }^{238} \mathrm{U}$ & $4.468(5) \times 10^{9} y$ & $8.202(60) \times 10^{15} y$ & $5.45(4) \times 10^{-5}$ & $1.98(3)$ & $7.3(11) \times 10^{-6}$ & $1.19(46) \times 10^{-5}$ & $6.3(5) \times 10^{-7}$ \\
\hline & ${ }^{234} \mathrm{Th}$ & $24.10(3) \mathrm{d}$ & & & & & & \\
\hline & ${ }^{234 \mathrm{~m}} \mathrm{~Pa}$ & 1.159(11) min & & $<1 \times 10^{-9}$ & & & & \\
\hline & ${ }^{234} \mathrm{~Pa}$ & $6.70(5) \mathrm{h}$ & & $<3 \times 10^{-10}$ & & & & \\
\hline & ${ }^{234} \mathrm{U}$ & $2.455(6) \times 10^{5} y$ & $1.5(0.2) \times 10^{16} y$ & $1.6(2) \times 10^{-9}$ & 1.63(15) & $1.7(7) \times 10^{-10}$ & $1.98(61) \times 10^{-10}$ & \\
\hline & ${ }^{230} \mathrm{Th}$ & $7.54(3) \times 10^{4} y$ & & $<4 \times 10^{-12}$ & & & & \\
\hline${ }^{235} \mathrm{U}$ & ${ }^{235} \mathrm{U}$ & $7.04(1) \times 10^{8} y$ & $0.98(28) \times 10^{19} y$ & $7.0(2) \times 10^{-9}$ & 1.86 & $5.9(6) \times 10^{-11}$ & $4.9(3) \times 10^{-11}$ & $9.5(5) \times 10^{-12}$ \\
\hline${ }^{232} \mathrm{Th}$ & ${ }^{232} \mathrm{Th}$ & $1.402(1) \times 10^{10} y$ & $1.22 \times 10^{21} \mathrm{y}$ & $1.1 \times 10^{-9}$ & $2.13(20)$ & $8.7(34) \times 10^{-10}$ & $3.1(4) \times 10^{-11}$ & $2.1(3) \times 10^{-13}$ \\
\hline
\end{tabular}

ation background normalized to the mass of sample in the energy range $40 \mathrm{keV}$ to $2.7 \mathrm{MeV}$ was determined to be $0.34,0.084$ and $0.81 \mathrm{~s}^{-1} \cdot \mathrm{kg}^{-1}$ for aluminum, titanium and glass, respectively. The background of fast neutrons normalized to the sample mass is determined mainly by spontaneous fission of ${ }^{238} \mathrm{U}$ and is equal to $7.3(11) \times$ $10^{-6}, 1.19(46) \times 10^{-5}$ and $6.3(5) \times 10^{-7} \mathrm{~s}^{-1} \cdot \mathrm{kg}^{-1}$ for aluminum, glass and titanium, respectively. The ${ }^{234} \mathrm{U}$ radioactivity has not been evaluated in the titanium sample. Therefore, the ${ }^{234} \mathrm{U}$ radioactivity was taken to be equal to ${ }^{238} \mathrm{U}$ radioactivity for equilibrium radioactive ${ }^{238} \mathrm{U}$ decay chain in the titanium sample. If the value of the spontaneous fission intensity normalized to the sample mass of the titanium is $9.3(16) \times 10^{-15} \mathrm{~s}^{-1} \cdot \mathrm{g}^{-1}$ assuming the spontaneous fission branching of ${ }^{234} \mathrm{U}$ is only $1.6(2) \times 10^{-9}(\%)$ then the radiation intensity of fast neutrons normalized to the sample mass is $1.51(4) \times 10^{-10} \mathrm{~s}^{-1} \cdot \mathrm{g}^{-1}$.

\section{References}

[1] Wurm, M., Goeger-Neff, M. and Hochmuth, K.A. (2007) Detection Potential for the Diffuse Supernova Neutrino Background in the Large Liquid-Scintillator Detector LENA. Physical Review D, 75, Article ID: 023007.

[2] Schön, R., Winkler, G. and Kustchera, W. (2004) A Critical Review of Experimental Data for the Half-Lives of the Uranium Isotopes ${ }^{238} \mathrm{U}$ and ${ }^{235} \mathrm{U}$. Applied Radiation and Isotopes, 60, 263-273.

[3] Holden, N.E. and Hoffman, D.C. (2000) Spontaneous Fission Half-Lives for Ground-State Nuclides. Pure and Applied Chemistry, 72, 1525-1562. http://dx.doi.org/10.1351/pac200072081525

[4] Garcia-Toraño, E. (2000) Alpha-Particle Emission Probabilities in the Decay of ${ }^{238}$ U. Applied Radiation and Isotopes, 52, 591-594. http://dx.doi.org/10.1016/S0969-8043(99)00215-8

[5] Browne, E. and Tuli, J.K. (2007) Nuclear Data Sheets for A = 234. Nuclear Data Sheets, 108, 681-772. http://dx.doi.org/10.1016/j.nds.2007.02.003

[6] Hadler, J.C., Bigazzi, G., Guedes, S., Iunes, P.J., Oddone, M., Tello, C.A. and Paulo, S.R. (2003) Spontaneous ${ }^{238}$ U Fission Half-Life Measurements Based on Fission-Track Techniques. Journal of Radioanalytical and Nuclear Chemistry, 256, 155-157.

[7] Firestone, R.B. (1998) Table of Isotopes [CD-ROM]. Lawrence Berkeley National Laboratory, Berkeley.

[8] Von Gunten, H.R., Grütter, A. and Reist, H.W. (1981) Ground-State Spontaneous-Fission Half-Lives of Uranium Isotopes. Physical Review C, 23, 1110-1112. http://dx.doi.org/10.1103/PhysRevC.23.1110

[9] Akovali, Y.A. (1994) Nuclear Data Sheets for A = 234. Nuclear Data Sheets, 71, 181-259. http://dx.doi.org/10.1006/ndsh.1994.1006

[10] Wang, S., Brice, P.B., Barmick, S.W., Moody, K.J. and Hulet, E.K. (1987) Radioactive Decay of U234 via Ne and Mg Emission. Physical Review C, 36, 2717. http://dx.doi.org/10.1103/PhysRevC.36.2717

[11] Tuli, J.K. (2011) Nuclear Wallet Cards. 8th Edition, National Nuclear Data Center, Brookhaven National Laboratory, New York.

[12] Artna-Cohen, A. (1997) Nuclear Data Sheets for A = 228. Nuclear Data Sheets, 80, 723-786. http://dx.doi.org/10.1006/ndsh.1997.0007

[13] Browne, E. (2005) Nuclear Data Sheets for A = 212. Nuclear Data Sheets, 104, 427-496. 
http://dx.doi.org/10.1016/j.nds.2005.01.002

[14] Browne, E. (2003) Nuclear Data Sheets for A = 235,239. Nuclear Data Sheets, 98, 665. http://dx.doi.org/10.1006/ndsh.2003.0005

[15] Chatani, H. (1983) A Measurement of the Averaged cross Section for the ${ }^{232} \mathrm{Th}(\mathrm{n}, 2 \mathrm{n})^{231} \mathrm{Th}$ Reaction with a Fission Plate. Nuclear Instruments and Methods, 205, 501-504. http://dx.doi.org/10.1016/0167-5087(83)90016-9

[16] Köhler, M., Degering, D. and Laubenstein, M. (2009) A New Low-Level g-Ray Spectrometry System for Environmental Radioactivity at the Underground Laboratory Felsenkeller. Applied Radiation and Isotopes, 67, 736-740.

[17] DIN 25482-5 (1993) Limit of Detection and Limit of Decision for Nuclear Radiation. Measurements-Part 5: Counting Measurements by High Resolution Gamma. Spectrometry, Neglecting the Influence of Sample Treatment. BeuthVerlag, Berlin.

[18] Erdtmann, G. and Petri, H. (1986) Nuclear Activation Analysis: Fundamentals and Techniques. In: Elving, P.J., Ed., Treatise on Analytical Chemistry (NY), Part 1, Vol. 14, 2nd Edition, John Wiley \& Sons, Inc., Hoboken. 
Scientific Research Publishing (SCIRP) is one of the largest Open Access journal publishers. It is currently publishing more than 200 open access, online, peer-reviewed journals covering a wide range of academic disciplines. SCIRP serves the worldwide academic communities and contributes to the progress and application of science with its publication.

Other selected journals from SCIRP are listed as below. Submit your manuscript to us via either submit@scirp.org or Online Submission Portal.
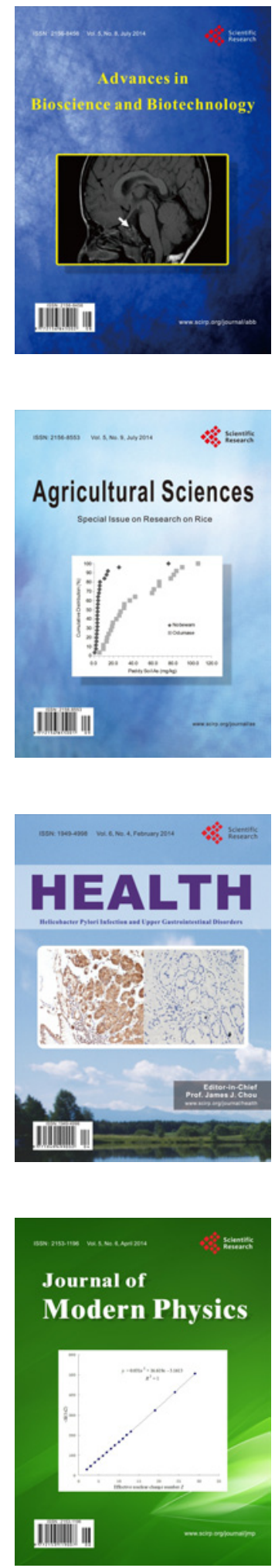
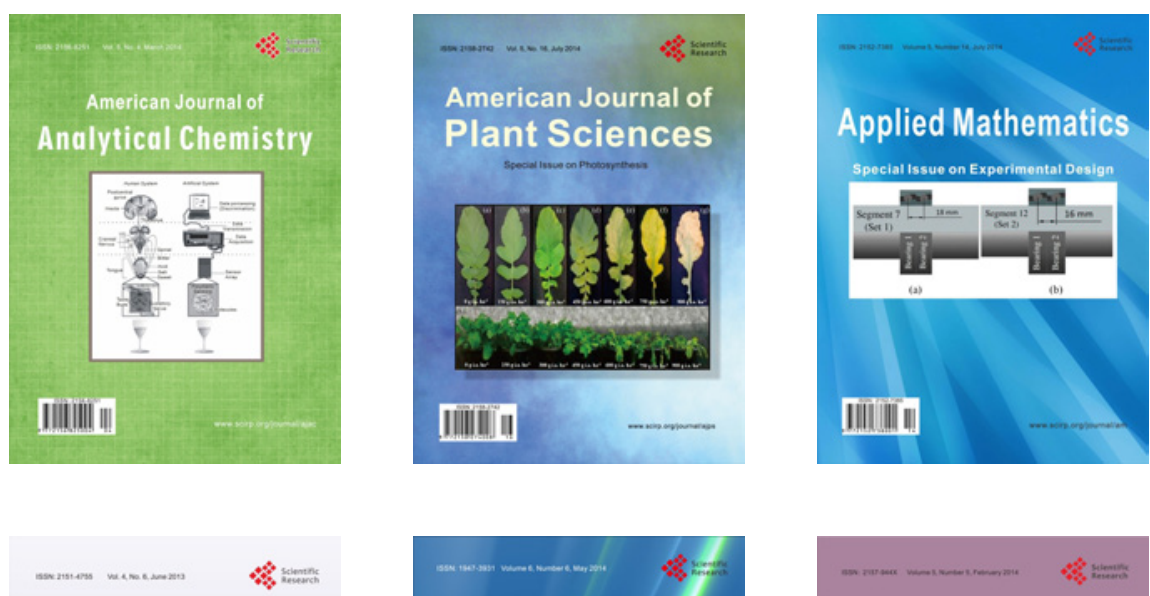

Creative Education
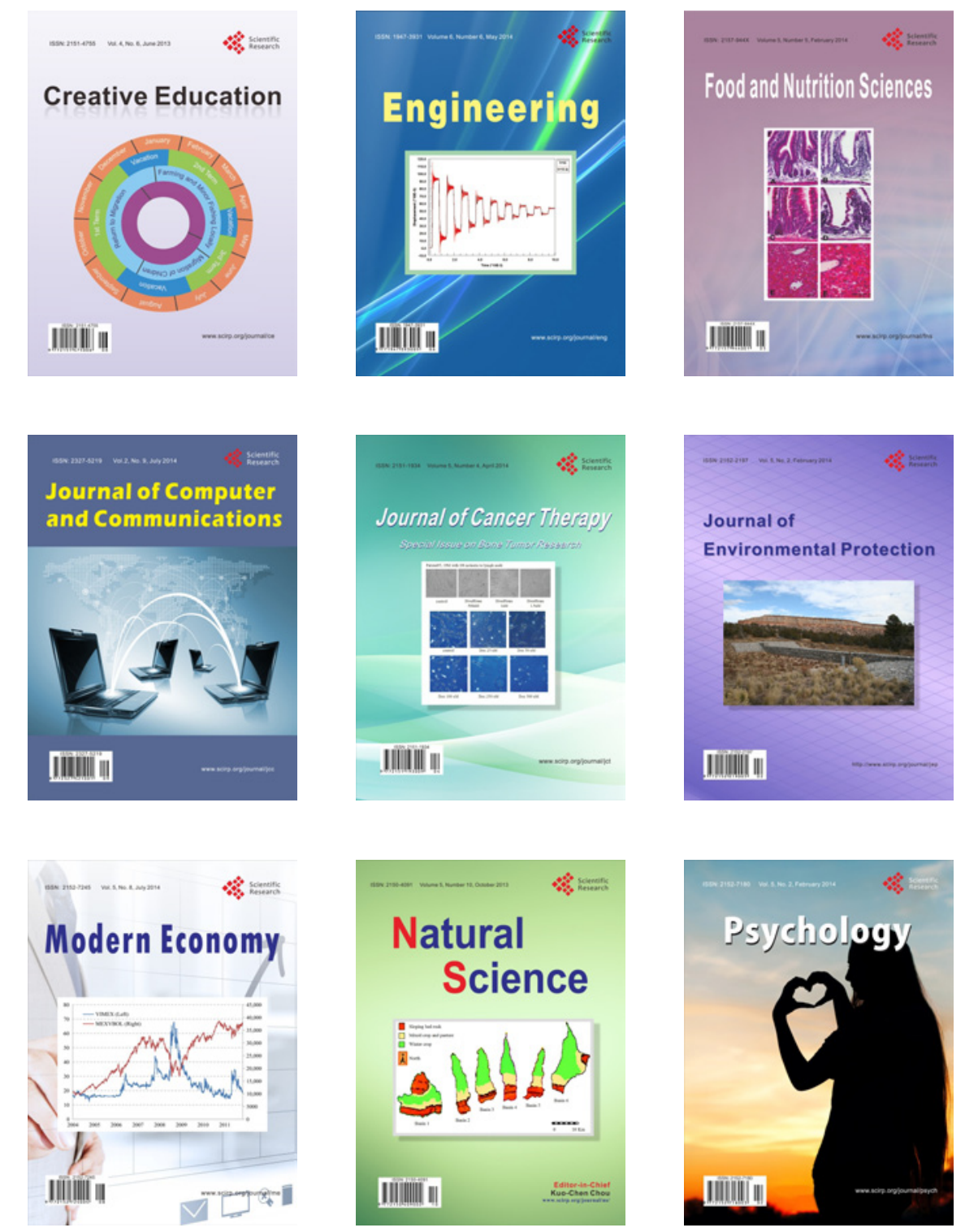